\title{
Marxismo e Libertação segundo Michael Löwy*
}

\author{
Paulo Roberto Pedrozo Rocha**
}

\begin{abstract}
RESUMO
Neste texto procuramos aproximar as considerações sócio-teológicas de Michael Löwy com a militância e o fazer teológico no Brasil e América Latina nos anos 70 e 80 . Busca-se ainda a reflexão sobre este momento histórico na vida teológica dos povos oprimidos e sua herança marcada nos estudos teológicos contemporâneos.
\end{abstract}

Palavras-chave: Michael Löwy - Teologia da Libertação - Política América Latina - Marxismo

\section{Marxism and Liberation according to Michael Löwy}

\begin{abstract}
In this text we try to approximate the socio-theological considerations of Michael Löwy with militancy and theological practice in Brazil and Latin America in the 70s and 80s. We also seek to reflect on this historical moment in the theological life of oppressed peoples and their heritage marked in contemporary theological studies.

Keywords: Michael Löwy - Liberation Theology - Politics - Latin America - Marxism
\end{abstract}

Para uma boa parte dos teólogos, nascidos deste lado do Globo que tem sido chamado de "terceiro mundo", ainda que esta designação esteja em desuso, o Marxismo exerceu e exerce uma dupla sedução: a

* Conferência oferecida durante o $24^{\circ}$ Seminário em Diálogo com o pensamento de Paul Tillich, sobre o tema Política, democracia e socialismo, em 07/06/2018. Por esse motivo, o artigo foi dispensado das exigências da revista quanto ao tamanho do texto (nota do editor).

** Bacharel em Teologia (Seminário Teológico Presbiteriano Independente de SP) e em Filosofia (Universidade de São Paulo), Mestre e Doutor em Filosofia (Universidade de São Paulo). Professor na Faculdade Messiânica de São Paulo. E.mail: teacherpauloroberto@, gmail.com. 
de se estar na vanguarda do pensamento social e, ao mesmo tempo, a de se ver comprometido com a práxis, palavra que parece emoldurar o elixir da convocação evangélica.

Isto tudo em meio a uma aparente contradição: a ênfase na objetividade das ações, o famoso referencial do materialismo histórico, parece lançar sombras nestas pretensas luzes. Como seria possível harmonizar o materialismo ateu com o kérigma da Palavra de Deus?

Diante da complexidade da questão, surgiu uma multiplicidade de respostas. Algumas no campo hermenêutico, como aquelas que, por exemplo, restringiam a teoria marxista a um mero "instrumental analítico". Para estes, a chave de leitura respondia pelo nome de Marxismo, nem tanto a prática.

Mas há também aqueles que viram na ação marxista o verdadeiro ponto de ação. Não há como deixar de se referir a exemplos como o do padre colombiano Camilo Torres Restrepo que se juntou ao Exército de Libertação Nacional de seu país, renunciando à ideia de que a pregação libertária deva se restringir a um exercício hermenêutico. Foi às armas, reconheceu na guerrilha o seu verdadeiro chamado e na morte em combate, deixou seu legado.

O que pretendemos analisar nesta conferência é uma parte, talvez muito pequena, deste emaranhado de ideias que até aqui anunciamos. Neste Seminário anual dedicado ao debate das ideias de um dos mais brilhantes teólogos cristãos do século XX, Paul Tillich, o tema provocador de nossas conversas é por demais oportuno: a política.

A política é em si uma construtora de paradoxos. Diante dela a maioria das pessoas quer se imiscuir. Ao tentar fazer isso, a totalidade delas acaba por se incluir na ação política. Não há nada que não seja política ao mesmo tempo em que não há entre nós uma só palavra que a possa conter.

Política é conceito que nasce plural. Aliás, é por acreditar que se vive melhor na companhia um dos outros é que se decide pela vida política. Logo na abertura do tratado "A Política" podemos ler:

Visto que toda cidade é um tipo de associação e que toda associação se forma tendo em vista algum bem (porque todos os homens sempre agem tendo em vista algo que lhes parece ser um bem), resulta claramente que, se todas as associações visam um certo bem, aquela que é a mais alta de 
todas e engloba todas as demais é precisamente a que visa ao bem mais alto de todos; ela é denominada cidade (pólis), ou comunidade política (ARISTÓTELES, 1987, p. 89).

Feitas estas considerações preliminares cabe agora apresentar nosso ponto de análise. Referência a partir da qual queremos tangenciar o pensamento tillichiano, cientes dos limites que qualquer aproximação do pensamento do teólogo terá que enfrentar. Propomos uma análise a partir das considerações sobre Cristianismo e Marxismo feitas pelo sociólogo Michael Löwy.

Michael Löwy é um sociólogo brasileiro, radicado na França desde a década de 60 do século passado, que tem sido responsável por uma análise muito apaixonada e, ao mesmo tempo, acurada do pensamento de Karl Marx. Na verdade, seus trabalhos mais recentes se debruçaram sobre a "Escola de Frankfurt" e a nostalgia do futuro que os frankfurtianos de todas as épocas manifestam ante o pensamento de Marx. As leituras de Benjamin marcam a produção recente deste pensador.

Em um texto não muito anterior a nossos dias, denominado $O$ Que é Cristianismo da Libertação: Religião e Política na América Latina, na verdade uma tradução para o português publicada em 2016 pela Editora Expressão Popular com o apoio da Fundação Perseu Abramo ${ }^{1}$ já em segunda edição, uma vez que a primeira edição pertenceu à Editora Vozes, Löwy refaz o percurso do encontro entre religião e política a partir dos referenciais cristãos, tomando em conta os exemplos das igrejas católica romana e protestante, analisando a influência que a Teologia da Libertação teve sobre as alas conservadora e progressista das referidas igrejas.

Uma instigante pergunta é formulada pelo autor ao final do terceiro capítulo do livro: terá acabado a Teologia da Libertação?

Após inventariar os fatos que na década de 90 do século XX podem ter contribuído para o obituário da Teologia da Libertação, para usar uma expressão que ele próprio utiliza, Löwy afirma que não, a Teologia da Libertação não acabou tampouco morreu: 1 O texto original é em inglês, publicado sob o nome The War of Gods-Religion and
Politics in Latin America. 
A primeira evidência que podemos observar é que, como movimento cultural e um corpo de pensadores engajados, a Teologia da Libertação está viva e indo muito bem... É verdade que houve uma evolução e que novas questões e problemas, novas formas de abordar a realidade social e religiosa no continente apareceram em seus escritos. Assim é que hoje, por exemplo, muitos desses textos dão uma atenção muito maior à espiritualidade e à religião popular. O conceito de "pobre foi ampliado, para incluir não só as vítimas do sistema econômico, mas também os oprimidos devido a sua cultura ou origem étnica - índios e negros. A situação especifica das mulheres, oprimidas duplamente nas sociedades patriarcais latino-americanas, também vem sendo cada vez mais levada em consideração (LÖWY, 2016, p. 201-202).

Não quero aqui historiar o livro de Löwy, embora sua agradável leitura torne esta tentação quase irresistível. Uma tese das mais interessantes apresentada no livro é o porquê se referir ao "cristianismo da libertação" ao invés de simplesmente "teologia da libertação".

Löwy defende que o chamado cristianismo da libertação é anterior à Teologia da Libertação. Na América Latina de um modo geral, e em particular no Brasil, ele teve o impulso das JUC's - Juventudes Universitárias Católicas que no final da década de 50 e no começo da década de 60 aproveitavam as chamadas "condições objetivas" ao lado das "condições subjetivas" para usar o jargão marxista, para se impor como alternativa à religiosidade piedosa tridentina manifestada na Igreja Católica.

O pontificado de João XXIII, visto como um período de abertura, favorece estas condições. Um particular da igreja católica no Brasil é também posto em relevância: a imensa influência da igreja francesa, identificada com uma certa corrente de esquerda, que despertava em seus clérigos e leigos um estudo pelas ideias de Marx e de outros pensadores identificados com ele.

A linha condutora de seu pensamento prossegue e chega no golpe civil militar de 1964. A princípio a igreja católica apoiou o golpe, mas aos poucos vai se distanciando dele para, no final da década de 60 e início da década de 70 revelar lideranças expressivas de oposição ao regime, dentro e fora do clero.

No final de seu texto surge uma identificação muito curiosa entre as origens do MST - Movimento dos Sem Terra e a religiosidade. Löwy 
busca nas experiências das Ligas Camponesas a partir de 1945 e na liderança de Francisco Julião as ideias seminais do que mais tarde se tornou a Pastoral da Terra e, em obediência ao tempo lógico, o Movimento dos Sem Terra. No mínimo original, a conferir.

Entretanto, para o trato da questão da relação entre Marxismo e Cristianismo sob o ponto de vista mais estrito, teórico como exige a ocasião, remeto a outro escrito de Löwy. Trata-se de um artigo publicado na Revista Lua Nova², edição de novembro de 1989, sob o título: Marxismo e Cristianismo na América Latina.

No texto o autor começa por destacar que o Marxismo fora primeiramente apresentado como a antítese da fé. Contudo, mudanças expressivas havidas na igreja latino-americana possibilitaram uma inclusão do pensamento marxista na práxis cristã.

Ao desenvolver sua análise prévia Löwy destacou o papel da inteligência americana no processo de combate à Teologia da Libertação. Ela havia sido descrita como um procedimento de infiltração deliberada, arquitetada por marxistas leninistas que objetivavam o poder. À parte dos absurdos de todas as épocas, há um elemento que gostaríamos de destacar que parece ter grande relevância quando analisamos o Marxismo e sua esfera de influência no cristianismo e/ou na religiosidade de um modo geral: o tema da cultura.

Ao destacar uma análise feita a pedido do então presidente americano George Bush (pai), Löwy transcreve o seguinte trecho do documento:

Se trata agora de tática gramsciana dos marxistas, que descobriram que o método mais promissor para chegar ao poder é dominando a cultura da nação, o que implica em um processo para lograr uma forte influência na religião, nas escolas, nos meios de comunicação e nas universidades. É neste contexto que se deve entender a Teologia da Libertação, como uma doutrina política disfarçada de crença religiosa com um significado anti-papal e anti-livre empresa, destinada a enfraquecer a independência da sociedade face ao controle estatista (LÖWY, 1989, p. 6).

2 A Revista Lua Nova é editada pelo Centro de Estudos de Cultura Contemporânea (CEDEC). Fundada em 1984 como uma revista de debate e intervenção nas grandes questões que mobilizavam a sociedade na época. Desde 1988 se apresenta com dossiês temáticos. Conta com o apoio do $\mathrm{CNPq}$, Capes, MinC dentre outras agências de fomento à pesquisa. $\mathrm{O}$ texto analisado neste artigo pode ser acessado em http://www.scielo.br/scielo.php?script=sci_arttext\&pid=S0102-64451989000400002\&lng=en\&nrm=iso 
A ideia aqui, ainda que exposta de forma grotesca pela anti intelligentsia supõe a religião como dado cultural, logo um artifício. Nesta condição, passível de manipulação e coerção social. De forma absolutamente involuntária, os inspetores americanos deram uma chave hermenêutica para interpretação do momento de libertação, no qual foi gestada a parceria cristianismo marxismo. A religião como cultura. É somente neste registro que o referido diálogo parece ser possível.

Löwy desconstrói a suposta influência intencional exercida por marxistas sobre a Teologia com a ideia de controle da instituição igreja para se chegar ao poder. Na verdade, para ele a pergunta que se impõe é: "por que no começo da década de 60, num espaço circunscrito, América Latina, uma parte do clero e dos leigos cristãos vão sentir a necessidade de usar o método marxista de interpretação e transformação da realidade?" (LÖWY, 1985, p. 7).

O caminho para responder a esta indagação parece inusitado. Michael Löwy utiliza uma publicação da Sagrada Congregação para a Doutrina da Fé, à época presidida pelo cardeal alemão Joseph Aloisius Ratzinger, mais tarde Papa Bento XVI, para dar um norte à questão. Nas palavras do cardeal:

Produziu-se no mundo ocidental um sensível vazio de alienação...as diversas formas de neomarxismo se transformaram em um élan moral e ao mesmo tempo em uma promessa de significação, que pareciam quase irresistíveis à juventude universitária...o desafio moral constituído pela pobreza e a opressão não podiam ser ignorados no momento em que a Europa e a América do Norte haviam atingido um grau de opulência desconhecido até então...não se pode negar que esta teologia combinando exegese bíblica e análise marxista é sedutora e de uma lógica quase sem falha (RATZINGER, 1985, p. 122-130).

Obviamente, no curso de sua argumentação Ratzinger irá apontar os erros que estão em seu modo de ver implicados nesta opção. Contudo, observa Löwy, trata-se de um olhar bastante interessante e por que não dizer acurado, da realidade da igreja e do cristianismo como um todo em uma época de grandes desafios e tomadas de posição.

Como é de se esperar a análise de Löwy não se contenta com as observações feitas por Ratzinger. Ele na verdade propõe um método, que pode ser observado até seus trabalhos mais recentes, que se cons- 
titui no uso da abordagem de Max Weber. No caso específico trata-se do conceito weberiano de afinidade eletiva.

Segundo o exposto por Weber, pondera Löwy, a partir de certas analogias, de certas afinidades, de certas correspondências, duas figuras culturais podem - em determinadas circunstâncias históricas - entrar em uma relação de atração, de escolha, de seleção, de eleição mútua. É um processo dinâmico conduzindo, em alguns casos, a uma simbiose ou até à fusão de duas estruturas significativas.

O passo seguinte é aplicar este referencial teórico à ligação entre cristianismo e socialismo ${ }^{3}$. As etapas são as seguintes:

a) Libertação dos Escravos e Oprimidos: lembrado como um imperativo bíblico-testamentário, simbolizado pela grande importância que as Comunidades de Base e os teólogos da Libertação de um modo geral dão ao livro do Êxodo, texto que concentra as narrativas de libertação dos descendentes de Jacó ${ }^{4}$ da situação de escravidão no Egito.

b) Valorização do Pobre: apresentado como vítima inocente e imune à corrupção dos poderosos. Ainda que haja uma distância conceitual entre o pobre retratado pelo cristianismo e o proletário da doutrina marxista, Löwy observa um certo parentesco entre estes conceitos. $\mathrm{O}$ pobre na doutrina tradicional cristã é objeto de caridade e proteção paternal, ao passo que o proletário é sujeito da ação revolucionária.

c) Universalismo e Internacionalismo: conceitos que fazem sentido na comunhão católica, palavra que significa universal e na pretensão histórica do socialismo como expressão internacional.

d) Crítica do Individualismo: neste momento o autor faz referência à obra de Lucien Goldmann sobre o filósofo Pascal, lembrando que no texto está dito que tanto o cristianismo como o marxismo rejeitam o individualismo puro. Para estas duas expressões os valores supremos são transindividuais, a saber, Deus para a religião e a comunidade humana para o socialismo.

e) Valorização da Comunidade: há uma crítica do anonimato, da impersonalidade, da alienação, da competição egoísta na vida moderna.

3 Neste momento, especificamente, Löwy prefere o termo socialismo à expressão marxismo.

4 Evitamos usar o termo Israel tendo em vista as recentes polêmicas em torno da verdade histórica de uma nacionalidade israelense levantadas pelos biblistas contemporâneos. 
f) Anticapitalismo: Löwy lembra que Max Weber apontava a existência de uma profunda oposição entre a racionalidade ética da Igreja Católica e a racionalidade econômica do capitalismo. A igreja rejeitaria um sistema econômico totalmente impessoal e reificado que escapa aos seus imperativos morais e religiosos. Estas observações são baseadas na obra Economia e Sociedade de Weber.

g) Esperança de um Reino de Justiça e Liberdade: aponta uma afinidade entre a utopia cristã e a utopia socialista sem aceitar a tese propagada por Berdiaev, dentre outros, segundo a qual o marxismo seria um avatar secularizado do messianismo judaico-cristão.

Ainda que sejam consideradas as diferenças de cada uma destas situações no âmbito do marxismo e do cristianismo, Löwy observa que o que transforma estas analogias puramente virtuais em relação dinâmica de afinidade eletiva é uma conjuntura histórica determinada em eventos que acontecem a partir do final da década de 50, justamente os fatos que mencionamos na abertura deste artigo e que foram retomados posteriormente na publicação de 1996.

Trata-se, portanto, de se referir ao instrumental marxista, mais do que à adesão ao marxismo como verdade. Na América Latina se encontrariam os dois quesitos básicos que no marxismo clássico oferecem os limites para a revolução: as condições objetivas e as condições subjetivas.

Como parte destas condições observou-se um desenvolvimento acelerado do capitalismo acompanhado de uma urbanização intensa e de rápida industrialização. Já a Revolução Cubana, que encerra a década de 50 e abre os anos 60 cria perspectivas para os entusiastas do socialismo, estão dadas as condições subjetivas.

É nesta conjuntura que vai se desenvolver, na América Latina, uma relação de afinidade eletiva, em certos setores da igreja e de sua base social, entre cristianismo e marxismo. Uma relação que, partindo das analogias existentes, vai conduzir a uma aproximação, convergência, articulação entre estas duas culturas tradicionalmente opostas - chegando em alguns casos até a fusão, com a formação de uma corrente marxista cristã (LÖWY, 1989, p. 11).

Ato contínuo, em uma análise das circunstâncias específicas da história, Löwy remete a três fatos importantes que ilustram a efetivação desta relação de afinidade: a esquerda cristã brasileira, a Teologia da Libertação e a Revolução Sandinista. 
No que se refere à Esquerda Cristã, Löwy recorre a exemplos

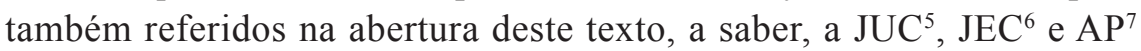
como a primeira forma que toma a articulação entre fé cristã e marxismo na América Latina. O diferencial destes movimentos é que se tratava de tomada de posição comunitária e não individual, dando assim respaldo à sua militância e a seus reclames.

Nossa atenção é deslocada para a anterioridade destes movimentos até mesmo em relação ao Concílio Vaticano II. Eles seriam por assim dizer seminais na estrutura teológica e eclesiástica. Uma boa expressão do que se passaria a denominar Teologia Prática.

Já a Teologia da Libertação não é a origem do Cristianismo Radical, para usar os termos de Löwy. Ele insiste em dizer que esta Teologia é o resultado de uma prática, de uma experiência anterior, que teria sido iniciada pela JUC brasileira no começo da década de 60 .

Antes do teólogo da libertação tivemos o bispo profético, o leigo comprometido e comunidades libertadoras...a teologia veio como segundo momento e veio como expressão desta prática libertadora da igreja. Isto significa que a Teologia da Libertação é a Teologia de uma Igreja de Libertação, de uma igreja que opta preferencialmente e solidariamente pelos pobres (LÖWY, 1989, p. 14).

A citação acima é feita com base no texto dos irmãos Boff (BOFF, L. e BOFF, C., 1985, p. 16) e reflete a posição da Teologia da Liberta-

\footnotetext{
Juventude Universitária Católica; associação civil católica reconhecida nacionalmente pela hierarquia eclesiástica em julho de 1950 como setor especializado da Ação Católica Brasileira (ACB). Seu objetivo era difundir os ensinamentos da Igreja no meio universitário. Desapareceu entre os anos de 1966 e 1968, quando a nova orientação da Conferência Nacional dos Bispos do Brasil (CNBB) em relação aos movimentos leigos da Igreja provocou o esvaziamento da ACB.

6 Juventude Estudantil Católica: associação civil católica reconhecida nacionalmente pela hierarquia eclesiástica em julho de 1950 como setor da Ação Católica Brasileira (ACB) encarregado de difundir os ensinamentos e a doutrina da Igreja junto aos estudantes de nível secundário. Desapareceu em 1966, quando a nova orientação firmada pela Conferência Nacional dos Bispos do Brasil (CNBB) levou ao esvaziamento da ACB e de seus ramos especializados.

7 Ação Popular: organização política de âmbito nacional, fundada durante um congresso promovido pela Juventude Universitária Católica (JUC) em Belo Horizonte, entre 31 de maio e 3 de junho de 1962. Integrada basicamente por membros da JUC e da Juventude Estudantil Católica (JEC), seu objetivo era formar quadros que pudessem "participar de uma transformação radical da estrutura brasileira em suapassagem do capitalismo para o socialismo".
} 
ção na cronologia dos fatos. Ela parte do princípio de que as condições objetivas da América Latina de pobreza e exploração dos pobres tenham favorecido o surgimento das condições subjetivas que apelaram à sensibilidade cristã através da solidariedade com os menos favorecidos.

O ponto sensível da Teologia da Libertação seria a solidariedade com o pobre. A grande diferença em relação ao que já vinha sendo praticado pela ação social da igreja é que o pobre não é mais vítima passiva, objeto de caridade e assistência, passando a ser sujeito de sua própria libertação. Esta é a novidade evangélica da Teologia da Libertação.

Por fim, na análise das três objetividades está a referência à Revolução Sandinista, ocorrida na Nicarágua na década de 70. Para Löwy é a primeira vez em que os cristãos não se colocam ao lado do poder. $\mathrm{Na}$ Nicarágua os cristãos participaram efetivamente do processo revolucionário e tomaram seu lugar no exercício do poder.

Desta forma, os cristãos deixaram de ser meros coadjuvantes. Quem sabe um prenúncio do que hoje novamente se espera de cristãos em uma América Latina ainda envolta em pobreza e desigualdades, que convoca seus agentes revolucionários que, por alguma razão interdita insistem em adormecer sob o manto da religiosidade criando uma não afinidade eletiva, dormindo um sonho dogmático.

Parafraseando as Escrituras e Marx: ... eis que estou à porta e bato: proletários de todo o mundo, uni-vos!

\section{Referências Bibliográficas}

ARISTÓTELES. A Política. Tradução de Leonel Vallandro e Gerd Bornheim da versão inglesa de W.A. Pickard. São Paulo: Nova Cultural, 1987.

BOFF, Leonardo e BOFF, Clodovis. Teologia da Libertação no Debate Atual. Petrópolis: Vozes, 1985.

LÖWY, Michael. O que é Cristianismo da Libertação? Religião e Política na América Latina. São Paulo: Editora Expressão Popular e Fundação Perseu Abramo, 2016.

. Marxismo e Cristianismo na América Latina. In Revista Lua Nova. São Paulo, CEDEC, n. ${ }^{\circ} 19$, novembro de 1989. Acesso em http://www. scielo.br/scielo.php?script=sci_arttext\&pid=S0102-64451989000400002\&lng $=$ en\&nrm $=$ iso.

RATZINGER, Joseph A. Les Conséquences Fondamentales d'une option Marxiste. Paris: Cerf, 1985. 